\title{
Limitations of current GABA agonists in neonatal seizures: toward GABA modulation via the targeting of neuronal $\mathrm{Cl}^{-}$ transport
}

\author{
Arjun Khanna ${ }^{1}$, Brian Patrick Walcott ${ }^{1}$ and KristopherT. Kahle ${ }^{1,2 *}$ \\ 1 Division of Neurosurgery, Department of Surgery, Massachusetts General Hospital, Harvard Medical School, Boston, MA, USA \\ ${ }^{2}$ Manton Center for Orphan Disease Research, Boston Children's Hospital, Boston, MA, USA
}

\section{Edited by:}

Karen Gale, Georgetown University, USA

\section{Reviewed by:}

Patricia Braga, Instituto de

Neurología, Uruguay

Steve C. Danzer, Cincinnati Children's

Hospital Medical Center, USA

\section{*Correspondence:}

Kristopher T. Kahle, Department of Neurological Surgery, Massachusetts General Hospital, Harvard Medical School, 55 Fruit Street, White Building Room 502, Boston, MA 02114, USA e-mail:kkahle@enders.tch.

harvard.edu
Neonatal intensive care has advanced rapidly in the last 40 years, with dramatic decreases in mortality and morbidity; however, for neonatal seizures, neither therapies nor outcomes have changed significantly. Basic and clinical studies indicate that seizures in neonates have long-term neurodevelopmental and psychiatric consequences, highlighting the need for novel pharmacotherapeutics. First-line treatments targeting GABAA receptors, like barbiturates and benzodiazepines, are limited in their efficacy and carry significant risks to the developing brain. Here, we review the use of current GABA agonist therapies for neonatal seizures and suggest other treatment strategies given recent developments in the understanding of disease pathogenesis. One promising avenue is the indirect manipulation of the GABAergic system, via the modulation of neuronal $\mathrm{Cl}^{-}$gradients, by targeting the cation- $\mathrm{Cl}^{-}$cotransporters (NKCC1 and $\mathrm{KCC} 2$ ) or their regulatory signaling molecules. This strategy might yield a novel class of more efficacious anti-epileptics with fewer side effects by specifically addressing disease pathophysiology. Moreover, this strategy may have ramifications for other adult seizure syndromes in which GABA receptor-mediated depolarizations play a pathogenic role, such as temporal lobe epilepsy.

Keywords: seizure, GABA, neonatal seizure, bumetanide, NKCC1, KCC2, WNK kinase, SPAK/OSR1 kinase

\section{CURRENT GABA AGONISTS AND PRODRUGS} (BENZODIAZEPINES AND BARBITURATES) ARE INADEQUATE IN THE TREATMENT OF NEONATAL SEIZURES

Seizures are the most common neurological emergency in the neonate, with an estimated prevalence of $1.8-5$ seizures/1000 live births in the US (Jensen, 2009). In fact, the lifespan risk of seizures is highest in the neonatal period. There are many conditions that may cause neonatal seizures, the most common of which is hypoxia/ischemia (Ronen et al., 1999; Tekgul et al., 2006) causing white matter injury (Figure 1). Seizures in the newborn can cause permanent and severe cognitive and behavioral abnormalities, as well as enhanced epileptogenicity later in life (Baram, 2003; Holmes, 2004; Swann, 2005), underlining the importance of effective therapy. Although neonatal seizures have a different etiology than adult seizures, current standard therapy involves compounds whose efficacy has only been well established in older patients. Benzodiazepines and barbiturates are the most common first-line therapies for neonatal seizures; however, the efficacy of these drugs in treating seizures in the newborn is not supported by robust evidence. The use of these drugs may have significant short- and long-term effects on brain development.

Current therapy for neonatal seizures is usually focused on early treatment with benzodiazepines and barbiturates. These drugs generally exert their effects via modulation of GABA action at the $\mathrm{GABA}_{\mathrm{A}}$ receptor, or by antagonism of NMDA receptors. Although these drugs are effective in adults, they do not control neonatal seizures well. When given as monotherapy, phenobarbital controls seizures in less than half of newborns (Painter et al., 1999). In a study examining six neonates treated with second-line benzodiazepines, none responded to this medication (Boylan et al., 2004). A Cochrane review concluded that there was little evidence from the literature that supported the use of these drugs in treating neonatal seizures (Booth and Evans, 2004). Furthermore, some have suggested that benzodiazepines and barbiturates may resolve the outward clinical symptoms of seizures due to sedation without correcting underlying abnormal brain activity, exacerbating "electroclinical dissociation" between clinical symptoms and electrographic recording and leading to an overestimation of the true efficacy of these drugs (Boylan et al., 2002).

Developmental changes in the expression and activity of neurotransmitters and their receptors provide some insight into the basis of the increased susceptibility of the neonatal brain to seizures and the relative inefficacy of benzodiazepines and barbiturates in controlling them. Developmentally regulated ion channel configurations that facilitate easier depolarization and an increased reliance on glutamatergic transmission together increase the excitability of the neonatal brain, putatively to promote synaptogenesis, but simultaneously conferring a disposition to seizures (Rakhade and Jensen, 2009). Differences in GABA signaling in the immature brain also contribute to its overall enhanced excitability. GABA is the major inhibitory neurotransmitter in the adult central nervous system, but its receptors and synthetic enzyme do not reach maximal levels of expression until the fourth postnatal week in rats (Swann et al., 1989; Brooks-Kayal et al., 2001). Furthermore, while 


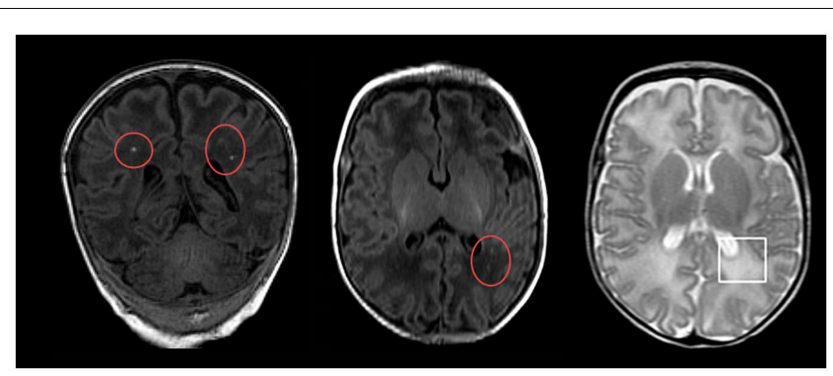

FIGURE 1 | Magnetic resonance imaging (MRI) of neonatal hypoxic-ischemia. Neonatal hypoxic-ischemia is a common cause of white matter injury, the underlying factor in the development of neonatal seizures. These manifest on MRI as either punctate white matter lesions (red circles; seen on T1-weighted MRI imaging) or diffuse excessive high signal intensity (white square; seen on T2-weighted MRI imaging). Reprinted from Wisnowski et al. (2013) under the terms of the Creative Commons Attribution License.

GABA hyperpolarizes adult neurons, it can depolarize neonatal neurons in vivo (Loturco et al., 1995). This may explain why benzodiazepines and barbiturates, which are $\mathrm{GABA}_{\mathrm{A}}$ receptor agonists, have limited efficacy in controlling neonatal seizures.

\section{SHORT-TERM SIDE EFFECTS OF BENZODIAZEPINES AND BARBITURATES}

In addition to limited efficacy, a growing body of evidence suggests that benzodiazepines and barbiturates cause short- and long-term harm to the developing neonatal brain. Cellular and neuromorphological effects of antiepileptic drugs have thus far only been extensively studied in rodent models, so further study is required to determine the acute neurotoxic effects of these drugs in humans.

In the neonatal rat, administration of any of the common antiepileptic drugs - phenytoin, phenobarbital, diazepam, clonazepam, vigabatrin, or valproate - all caused apoptotic neurodegeneration that was associated with reduced expression of neurotrophins (Bittigau et al., 2002). Importantly, these detrimental effects are consequences of the mechanism of action of these drugs and not cross-reactivity, pharmacokinetics, or other compoundspecific toxicities. For example, apoptotic neurodegeneration is seen in phenobarbital and diazepam, but also in other anesthetics that agonize the $\mathrm{GABA}_{\mathrm{A}}$ receptor (Jevtovic-Todorovic et al., 2003). Observations of apoptosis following anesthetics that agonize $\mathrm{GABA}_{\mathrm{A}} \mathrm{Rs}$ have also been reported in non-human primates, suggesting a similar effect in humans. For example, isofluorane, whose mechanism of action includes activation of $\mathrm{GABA}_{\mathrm{A}} \mathrm{Rs}$, induces neuro-apoptosis in neonatal rhesus macaques (Brambrink et al., 2010, 2012).

The two most common classes of anti-convulsant drugs are $\mathrm{GABA}_{\mathrm{A}}$ receptor agonists and NMDA receptor antagonists. Both NMDA receptor antagonists (Haberny et al., 2002; Hansen et al., 2004) and $\mathrm{GABA}_{\mathrm{A}}$ receptor agonists (Bittigau et al., 2002) cause the activation of apoptotic pathways and down-regulate neurotrophins, which together cause apoptotic neurodegeneration and inhibit neurogenesis, particularly in regions of substantial neural growth in the early postnatal period such as the sub-ventricular zone of lateral ventricles, cerebellum, and the subgranular zone of the hippocampal dentate gyrus. Anticonvulsants that antagonize NMDA receptors or agonize $\mathrm{GABA}_{\mathrm{A}}$ receptors cause significant changes in the neonatal rat cerebral cortex proteome as soon as 1 day following therapy, including deregulation of proteins associated with apoptosis, oxidative stress, inflammation, proliferation, and potentiation, suggesting a multitude of mechanisms by which such early exposure may result in neurodegeneration (Kaindl et al., 2008). Barbiturates may also alter the development of synaptic junctions (Dydyk and Rutczynski, 1980).

The adverse effects of antiepileptic drugs are age-dependent. The rodent brain undergoes a period of increased synaptogenesis, glial cell multiplication, myelination, and brain network reorganization in the first three postnatal weeks (Dobbing, 1974), during which the neonatal rat is most susceptible to developmental toxicity from antiepileptic drugs (Kaindl et al., 2008). The corresponding brain growth in humans begins during pregnancy and lasts up to the third postnatal year (Dobbing, 1974; Herschkowitz, 1988), also suggesting enhanced susceptibility to toxicity during this period.

The changes in cell proliferation and survival signaling pathways induced by common antiepileptic drugs likely contribute to altered brain morphology that is observed soon after developmental exposure (Figure 2). Decreased gray matter volume and altered gray matter morphology in a number of brain regions following developmental exposure to antiepileptic drugs is seen in rodents (Ikonomidou et al., 2007). Early barbiturate administration is consistently associated with decreased brain weight (Schain and Watanabe, 1975; Diaz et al., 1977) and neuronal number (Yanai et al., 1979) throughout rodent life, which is likely related to both apoptotic neurodegeneration and inhibited neurogenesis.

\section{LONG-TERM SIDE EFFECTS OF BENZODIAZEPINES AND BARBITURATES}

Determination of long-term cognitive and behavioral effects of early treatment with common anticonvulsants is difficult because cognition, behavior, and neuromorphology later in life is frequently heavily confounded by the condition for which anticonvulsant therapy was initially prescribed. However, there is general consensus that neonatal therapy with agents that interfere with GABA or glutamate transmission, including benzodiazepines, barbiturates, and phenytoin, cause cognitive and behavioral defects later in life. These cognitive and behavioral defects have been reported in both animal models and in humans.

Cognitive and behavioral deficits are likely caused by apoptotic neurodegeneration and inhibited neurogenesis in proliferative cells in the immature brain, and by changes in neural organization caused by the death of these neurons. Short-term drug-induced inhibition of neurogenesis can indirectly lead to destruction of pre-formed nerve populations and can thereby have a much broader impact on morphology later in development. For example, neonatal administration of phenobarbital led to a destruction of cerebellar and hippocampal granule cells, which form early in the postnatal period, as well as cerebellar Purkinje and hippocampal pyramidal neurons, which are formed prenatally, before phenobarbital was administered (Yanai et al., 1981). Since prenatally formed nerve cell populations are culled during synaptogenesis in normal brain development, barbiturate-induced 

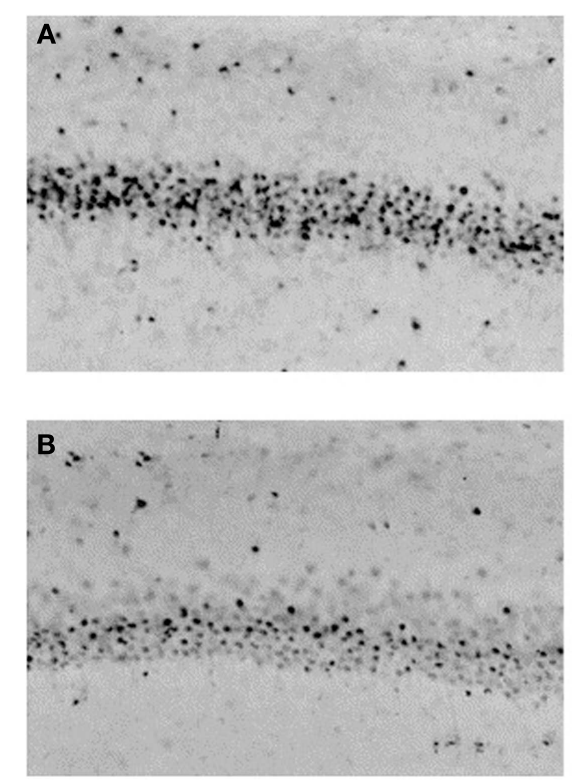

FIGURE 2 | GABA agonists affect the development of the neonatal brain. Muscimol, a potent selective agonist for the $G_{A B A}$ receptor, was administered to neonatal rats on postnatal days 0 and 1 , and histologic specimens were obtained on postnatal day 21. Representative photomicrographs illustrate neuronal nuclear antigen-immunoreactive
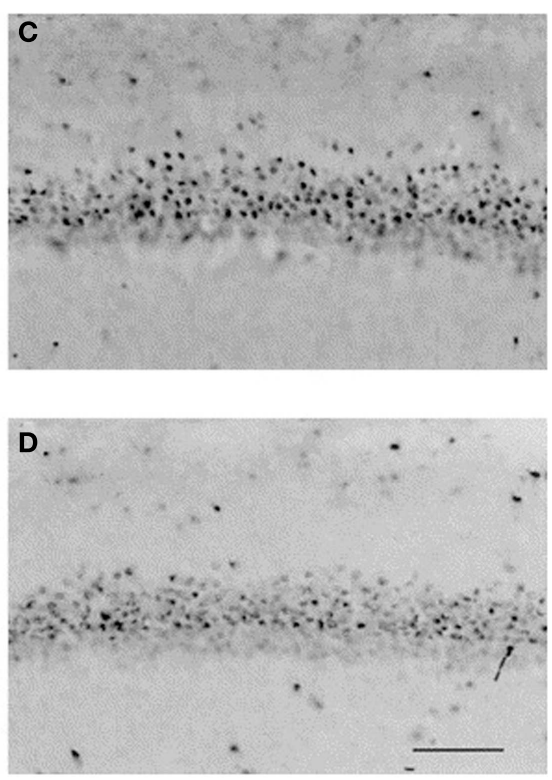

neurons in the CA1 region of the hippocampus in (A) sham males, (B) males + muscimol, (C) sham females, and (D) females + muscimol. Musciol treated rats have fewer neurons in the CA1 region of the hippocampus than their sham counterparts. Scale bar $=100 \mu \mathrm{m}$. Reprinted from Nunez et al. (2003), with permission from Elsevier. destruction of presynaptic cells that ordinarily mature in the postnatal period can lead to a reduction in the number of prenatally formed postsynaptic neurons even without direct toxicity to these cells, since these pre-formed populations rely on synaptogenesis for survival through culling during development (Fishman and Yanai, 1983). In this way, even minor neurodegeneration or modulation of synaptogenesis during critical neurodevelopmental periods in the neonate can have major long-term effects on network organization and cognitive and behavioral deficits.

There is a wide array of reported cognitive and behavioral changes that are associated with early anticonvulsive therapy. Rats receiving phenobarbital show increased agitation, activity level, and aggression (Diaz and Schain, 1978). Adult rats that received early barbiturate therapy perform worse in cognitive tasks aimed at assessing hippocampal function (Yanai et al., 1989). Exposure to phenobarbital, phenytoin, or lamotrigine during the second postnatal week resulted in adult deficits in spatial learning, sensorimotor gating, and other behaviors in rats (Forcelli et al., 2012). The benzodiazepine diazepam has been shown to interfere with learning and memory in rats (Pereira et al., 1989; Holley et al., 1995). One study found that although phenobarbital therapy did reduce the number of seizures in developing rats, the cognitive deficits that resulted from phenobarbital therapy were greater in severity than the deficits in rats that did not receive phenobarbital, despite the fact that the latter group suffered more seizures (Mikati et al., 1994). Phenytoin therapy altered schedule-controlled behavior in rats that outlasted the therapy itself (Krafft et al., 1982).

Human studies also describe similar cognitive deficits. Children aged between 6 months to 3 years who were placed on 1 year of phenobarbital therapy after suffering from febrile seizures showed a negative correlation between serum levels of phenobarbital and memory concentration subscore of the Binet IQ test, although no significant difference in overall IQ or parentreported behavior compared to controls was reported at 8 or 12 months of follow-up (Camfield et al., 1979). In a much larger study of 217 children aged between 8 and 36 months with febrile seizures, phenobarbital use significantly lowered IQ after 2 years compared to controls, but was not associated with a significant reduction in seizure recurrence (Farwell et al., 1990). Upon testing 3-5 years after medication had been stopped, early phenobarbital use significantly lowered performance in language/verbal tests and was associated with a reduction in IQ (Sulzbacher et al., 1999).

\section{NOVEL TARGETS OF THE GABAergic SYSTEM: TARGETING MOLECULES THAT ESTABLISH CI- GRADIENTS}

In the adult nervous system, due to low intracellular levels of $\mathrm{Cl}^{-}$, GABA inhibits most neurons by activation of $\mathrm{GABA}_{\mathrm{A}}$ Rs, causing $\mathrm{Cl}^{-}$influx, membrane hyperpolarization, and inhibition. Additionally, $\mathrm{GABA}_{\mathrm{A}} \mathrm{R}$ activation can also inhibit neurons via "shunting inhibition" by decreasing membrane resistance, which decreases the efficacy of excitatory signals to reach the critical threshold of action potential generation (Farrant and Kaila, 2007). Under several normal or pathophysiological circumstances, however, GABA can depolarize and even excite neurons rather than inhibit them. For example, in immature neurons during development and in certain neural subpopulations in pathophysiological states, GABA triggers depolarizations, and potential excitation (Cherubini et al., 1991; Ben-Ari et al., 1994), for review see (Marty and Llano, 2005). 

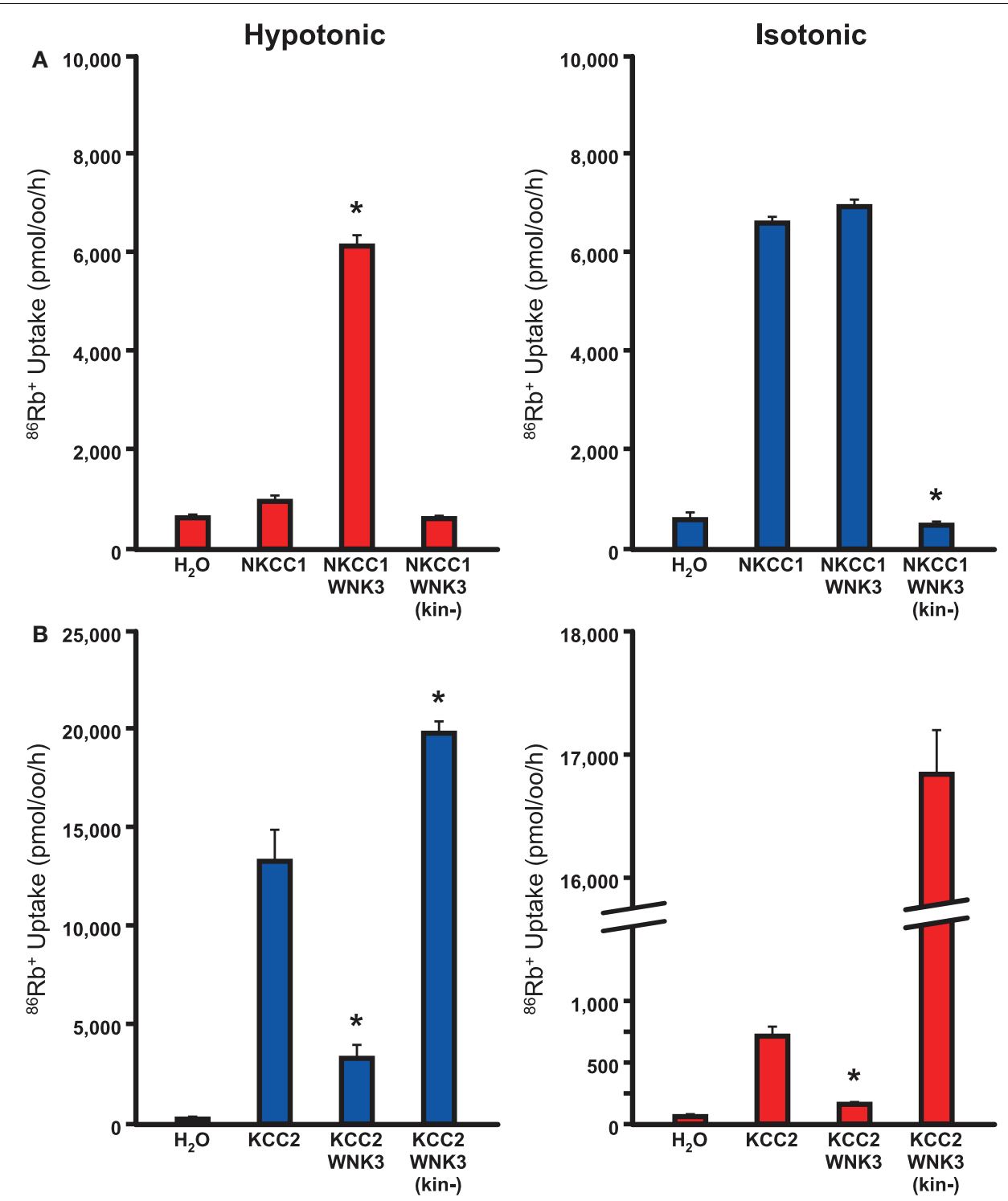

FIGURE 3 | WNK3 has opposite effects on NKCC1 and KCC2. Xenopus oocytes were injected with cRNAs encoding NKCC1 (A) or KCC2 (B) alone and in combination with wild-type or kinase-dead mutant WNK3. $86 \mathrm{Rb}+$ influx through NKCC1 (A) or efflux through KCC2 (B) was determined as a measure of flux through these cation $\mathrm{Cl}$-channels. (A) WNK3 activates NKCC1. NKCC1 normally shows little activity under hypotonic conditions (180 mosM) and is active in isotonic conditions (200 mM). WNK3 increases NKCC1 to maximal activity in both conditions. Kinase-dead WNK3 strongly inhibits NKCC1 activity,

indicating phosphorylation of NKCC1 by WNK3 is necessary for activity. ${ }^{*}, P<0.0001$ vs. NKCC1 alone. (B) WNK3 inactivates KCC2. KCC2 is partially active under isotonic conditions and active under hypotonic conditions. WNK3 inhibits KCC2 under both conditions. Kinase-dead WNK3 strongly activates KCC2 under both hypotonic and isotonic conditions. ${ }^{*}, P<0.0001$ vs. KCC2 alone. Taken together, these data suggest that WNK3 is an important regulator of NKCC1 and KCC2 activity. Its kinase activity activates NKCC1 and inhibits KCC2. Figure represents data from Kahle et al. (2005).

Although some have suggested that the observation of excitatory GABA responses is experimental artifact resulting from cellular damage in exvivo studies (Bregestovski and Bernard, 2012), a large and growing body of evidence has confirmed excitatory GABA signaling in the developing brain in vivo and its physiological significance during development (Ben-Ari et al., 2012).

The depolarizing effect of GABA results from a change in the $\mathrm{GABA}_{\mathrm{A}}$ reversal potential $\left(\mathrm{E}_{\mathrm{GABA}}\right)$ often secondary to an increased neuronal accumulation of $\mathrm{Cl}^{-}$, though $\mathrm{HCO}_{3}^{-}$also plays a role.

Several notable ion channels and transporters are integral for neuronal $\mathrm{Cl}^{-}$homeostasis. Among these are the bumetanide-sensitive $\mathrm{Na}^{+}-\mathrm{K}^{+}-\mathrm{Cl}^{-}$co-transporter NKCCl, which transports $\mathrm{Cl}^{-}$into the cell, and KCC2, which normally extrudes it (Kahle et al., 2008b; Blaesse et al., 2009) (Figure 3).

In immature neurons, the $\mathrm{Cl}^{-}$-exporting activity of $\mathrm{KCC} 2$ is lower than in mature neurons (Rivera et al., 1999), and in the context of NKCC1 expression, neuronal $\left[\mathrm{Cl}^{-}\right]_{\mathrm{i}}$ is higher and $\mathrm{E}_{\mathrm{GABA}}$ is more depolarized (Figure 3B). Moreover, long runs of 
action potentials in single neurons (Woodin et al., 2003), or prolonged seizures may result in an activity-dependent accumulation of intracellular $\mathrm{Cl}^{-}$(Khalilov et al., 2003; Dzhala et al., 2010). These data might provide insight as to why traditional anti-seizure medications are less effective when given later in the course of neonatal seizures (Painter et al., 1999).

Ion transport proteins that establish $\mathrm{Cl}^{-}$gradients across neuronal membranes and contribute to depolarizing GABA responses in the immature brain could be novel targets for modulation of the GABAergic system in treating neonatal seizures (Kahle et al., 2008b). The commonly used loop diuretic bumetanide has a higher affinity for NKCC1 than KCC2 at low concentrations (Isenring et al., 1998; Hannaert et al., 2002). In a human neonate in status epilepticus (Kahle et al., 2009) and in animal models of status epilepticus (Dzhala et al., 2005), bumetanide reduces electrographic seizures and exhibits synergy with phenobarbital, which increases the open probability of the $\mathrm{GABA}_{\mathrm{A}}$ channel (Dzhala et al., 2008).

While several studies have reported anti-convulsant effects of bumetanide (Schwartzkroin et al., 1998; Reid et al., 2000; Mazarati et al., 2009), others have found no significant anti-convulsant effect (Ostergaard et al., 1972; Mares, 2009; Minlebaev and Khazipov, 2011). Most of the studies that demonstrate efficacy of bumetanide were performed when it was administered with an anesthetic or other drug that has GABA-modulatory effects, like phenobarbital. Other NKCC1 inhibitors with greater blood-brain-barrier penetration may have improved efficacy. Bumetanide pro-drugs that mask the hydrophilic acid group with esters to facilitate transport into the brain before releasing the active molecule are currently being tested (Loscher et al., 2013).

Currently there are two clinical trials evaluating bumetanide as a treatment for neonatal seizures. A phase I trial (NCT00830531) is actively enrolling patients in a randomized, double-blind, controlled dose-escalation study of bumetanide as an add-on therapy to treat refractory seizures caused by hypoxic-ischemic encephalopathy. The estimated study completion date is December 2015. A second trial (NCT01434225) is being performed by a large, multi-center European group in an "open-label," doseescalation fashion to assess the effect of bumetanide in addition to phenobarbital for the treatment of neonatal seizures caused by hypoxic-ischemic encephalopathy. Data from these pilot studies will be utilized to guide the design of larger Phase III trials that will determine the efficacy of bumetanide in the treatment of neonatal seizures.

There are some concerns about the modulation of depolarizing GABA responses based on its importance during neurodevelopment. Studies suggest the "premature" shift of $\mathrm{E}_{\mathrm{GABA}}$ via NKCC1-knockdown or KCC2-overexpression may result in cortical neurons with fewer and shorter dendrites (Cancedda et al., 2007), less mature dendritic spines with decreased density and increased lengths, and fewer glutamatergic inputs received by cortical pyramidal neurons (Wang and Kriegstein, 2008). Some of these observations have also been recapitulated in rats (Wang and Kriegstein, 2011). More rigorous, long-term follow-up in neonates receiving bumetanide therapy is required, including comparison with current therapies, to determine neuropsychiatric sequelae associated with modulation of neuronal $\mathrm{Cl}^{-}$gradients in GABA

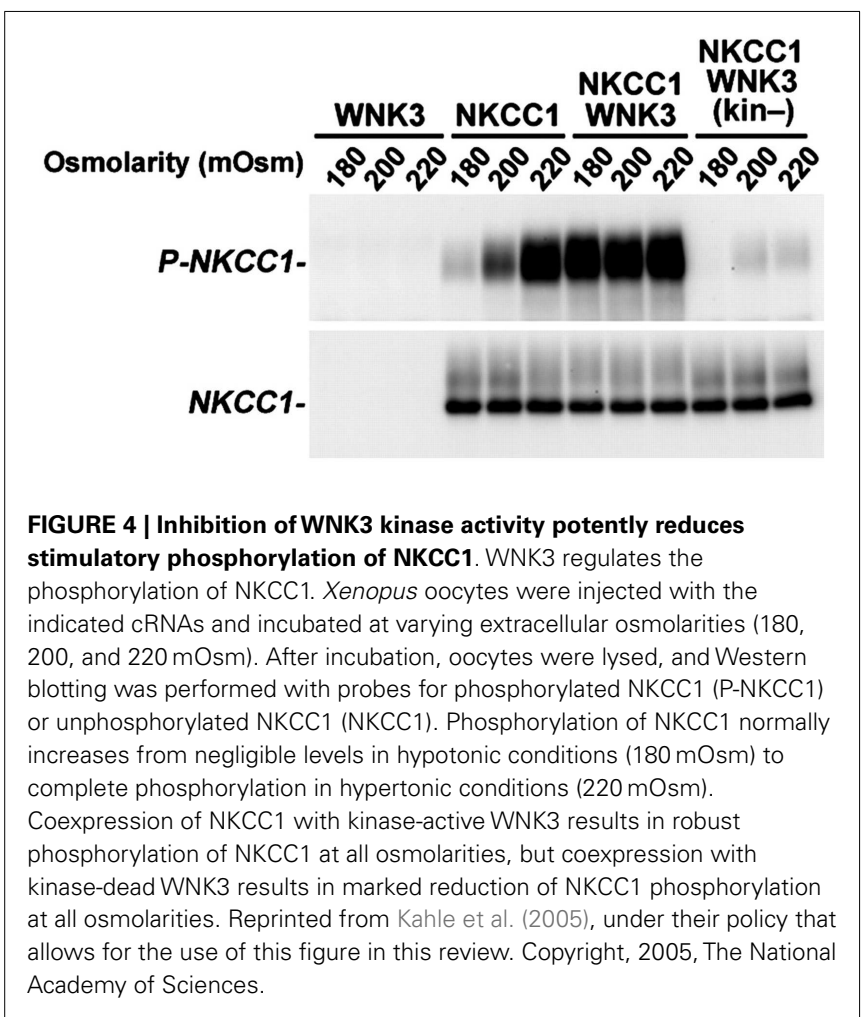

transmission. Nevertheless, in the context of our enhanced understanding of the mechanisms of GABA signaling in the neonatal brain, novel therapies that target $\mathrm{Cl}^{-}$homeostasis are promising new targets for the treatment of neonatal seizures (Loscher et al., 2013). Alternative mechanisms to modulate neuronal $\mathrm{Cl}^{-}$homeostasis should also be considered. One unexplored mechanism of $\mathrm{Cl}^{-}$modulation is the manipulation of neuronal $\mathrm{Cl}^{-}$gradients via targeting of the serine-threonine regulatory kinases of NKCC1 and KCC2 (Kahle et al., 2010). For example, phosphorylation of NKCC1 at critical N-terminal threonine residues is required for transporter activity, and this event is catalyzed by the WNK/SPAK kinase cascade (for review, see Kahle et al., 2008a). Inhibition of WNK3 kinase activity, a molecule expressed highly in the developing brain, is the most potent means of concurrently inhibiting NKCC1 activity and activating KCC2 activity in vitro, and does so via changes in transporter phosphorylation at critical regulatory residues (Figure 4) (Kahle et al., 2005; de Los Heros et al., 2006). Given the coordinated but reciprocal stimulatory and inhibitory effect of phosphorylation on NKCC1 and KCC2, respectively, we propose that inhibition of the WNK/SPAK pathway in neurons might help restore GABA inhibition. These hypotheses are currently being explored in neuronal culture systems and whole animal models of seizures in multiple labs, including our own. These efforts may prove useful not only for neonatal seizure management, but also for adult seizure syndromes that exhibit depolarized GABA responses and altered $\mathrm{Cl}^{-}$homeostasis, such as temporal lobe epilepsy, in which abnormal expression of $\mathrm{Cl}^{-}$channels also renders GABA excitatory (Palma et al., 2006; Huberfeld et al., 2007; Munoz et al., 2007; Brandt et al., 2010; Maa et al., 2011; Miles et al., 2012; Eftekhari et al., 2013). 


\section{REFERENCES}

Baram, T. Z. (2003). Long-term neuroplasticity and functional consequences of single versus recurrent early-life seizures. Ann. Neurol. 54, 701-705. doi:10.1002/ ana. 10833

Ben-Ari, Y., Tseeb, V., Raggozzino, D., Khazipov, R., and Gaiarsa, J. L. (1994). $\gamma$-Aminobutyric acid (GABA): a fast excitatory transmitter which may regulate the development of hippocampal neurones in early postnatal life. Prog. Brain Res. 102, 261-273. doi:10.1016/S00796123(08)60545-2

Ben-Ari, Y., Woodin, M. A., Sernagor, E., Cancedda, L., Vinay, L., Rivera, C., et al. (2012). Refuting the challenges of the developmental shift of polarity of GABA actions: GABA more exciting than ever! Front. Cell. Neurosci. 6:35. doi:10.3389/ fncel.2012.00035

Bittigau, P., Sifringer, M., Genz, K., Reith, E., Pospischil, D., Govindarajalu, S., et al. (2002). Antiepileptic drugs and apoptotic neurodegeneration in the developing brain. Proc. Natl. Acad. Sci. U.S.A. 99, 15089-15094. doi:10.1073/pnas.222550499

Blaesse, P., Airaksinen, M. S., Rivera, C., and Kaila, K. (2009). Cation-chloride cotransporters and neuronal function. $\mathrm{Neu}$ ron 61, 820-838. doi:10.1016/ j.neuron.2009.03.003

Booth, D., and Evans, D. J. (2004). Anticonvulsants for neonates with seizures. Cochrane Database Syst. Rev. 3:CD004218. doi:10.1002/ 14651858.CD004218.pub2

Boylan, G. B., Rennie, J. M., Chorley, G., Pressler, R. M., Fox, G. F., Farrer, K., et al. (2004). Second-line anticonvulsant treatment of neonatal seizures: a video-EEG monitoring study. $\mathrm{Neu}$ rology 62, 486-488. doi:10.1212/ 01.WNL.0000106944.59990.E6

Boylan, G. B., Rennie, J. M., Pressler, R. M., Wilson, G., Morton, M., and Binnie, C. D. (2002). Phenobarbitone, neonatal seizures, and video-EEG. Arch. Dis. Child. Fetal Neonatal Ed. 86, F165-F170. doi:10.1136/fn.86.3.F165

Brambrink, A. M., Back, S. A., Riddle, A., Gong, X., Moravec, M. D., Dissen, G. A., et al. (2012). Isoflurane-induced apoptosis of oligodendrocytes in the neonatal primate brain. Ann. Neurol. 72, 525-535. doi:10.1002/ ana. 23652

Brambrink, A. M., Evers, A. S., Avidan, M. S., Farber, N. B., Smith,
D. J., Zhang, X., et al. (2010). Isoflurane-induced neuroapoptosis in the neonatal rhesus macaque brain. Anesthesiology 112, 834-841. doi:10.1097/ ALN.1090b1013e3181d1049cd

Brandt, C., Nozadze, M., Heuchert, N., Rattka, M., and Loscher, W. (2010). Disease-modifying effects of phenobarbital and the NKCC1 inhibitor bumetanide in the pilocarpine model of temporal lobe epilepsy. J. Neurosci. 30, 8602-8612. doi:10. 1523/JNEUROSCI.0633-10.2010

Bregestovski, P., and Bernard, C. (2012). Excitatory GABA: how a correct observation may turn out to be an experimental artifact. Front. Pharmacol. 3:65. doi:10.3389/fphar.2012.00065

Brooks-Kayal, A. R., Shumate, M. D., Jin, H., Rikhter, T. Y., Kelly, M. E., and Coulter, D. A. (2001). $\gamma$-Aminobutyric acidA receptor subunit expression predicts functional changes in hippocampal dentate granule cells during postnatal development. J. Neurochem. 77, 1266-1278. doi:10.1046/j.14714159.2001.00329.x

Camfield, C. S., Chaplin, S., Doyle, A.B., Shapiro, S. H., Cummings, C., and Camfield, P. R. (1979). Side effects of phenobarbital in toddlers; behavioral and cognitive aspects. J. Pediatr. 95, 361-365. doi:10.1016/S00223476(79)80507-7

Cancedda, L., Fiumelli, H., Chen, K., and Poo, M.-M. (2007). Excitatory GABA action is essential for morphological maturation of cortical neurons in vivo. J. Neurosci. 27, 5224-5235. doi:10.1523/ JNEUROSCI.5169-06.2007

Cherubini, E., Gaiarsa, J. L., and Ben-Ari, Y. (1991). GABA: an excitatory transmitter in early postnatal life. Trends Neurosci. 14, 515-519. doi:10.1016/ 0166-2236(91)90003-D

de Los Heros, P., Kahle, K. T., Rinehart, J., Bobadilla, N. A., Vazquez, N., San Cristobal, P., et al. (2006). WNK3 bypasses the tonicity requirement for $\mathrm{K}-\mathrm{Cl}$ cotransporter activation via a phosphatasedependent pathway. Proc. Natl. Acad. Sci. U.S.A. 103, 1976-1981. doi:10.1073/pnas.0510947103

Diaz, J., and Schain, R. J. (1978). Phenobarbital: effects of long-term administration on behavior and brain of artificially reared rats. Science 199, 90-91. doi:10.1126/science.199.4324.90

Diaz, J., Schain, R. J., and Bailey, B. G. (1977). Phenobarbital-induced brain growth retardation in artificially reared rat pups. Biol. Neonate 32, 77-82. doi:10.1159/000240998

Dobbing, J. (1974). The later growth of the brain and its vulnerability. Pediatrics 53, 2-6.

Dydyk, L., and Rutczynski, M. (1980). Development of neuropil and synaptic junctions in brain cortex and stem of rabbit newborns after the transplacental action of luminal. Acta Med. Pol. 21, $1-10$.

Dzhala, V. I., Brumback, A. C., and Staley, K. J. (2008). Bumetanide enhances phenobarbital efficacy in a neonatal seizure model. Ann. Neurol. 63, 222-235. doi:10.1002/ ana.21229

Dzhala, V. I., Kuchibhotla, K. V., Glykys, J. C., Kahle, K. T., Swiercz, W. B., Feng, G., et al. (2010). Progressive NKCC1-dependent neuronal chloride accumulation during neonatal seizures. J. Neurosci. 30, 11745-11761. doi:10.1523/ JNEUROSCI.1769-10.2010

Dzhala, V. I., Talos, D. M., Sdrulla, D. A., Brumback, A. C., Mathews, G. C., Benke, T. A., et al. (2005). NKCC1 transporter facilitates seizures in the developing brain. Nat. Med. 11, 1205-1213. doi:10.1038/nm1301

Eftekhari, S., Mehvari Habibabadi, J., Najafi Ziarani, M., Hashemi Fesharaki, S. S., Gharakhani, M., Mostafavi, H., et al. (2013). Bumetanide reduces seizure frequency in patients with temporal lobe epilepsy. Epilepsia 54, e9-12. doi:10.1111/j.15281167.2012.03654.x

Farrant, M., and Kaila, K. (2007). "The cellular, molecular and ionic basis of GABAA receptor signalling," in Progress in Brain Research, eds E. D. A. James, M. Tepper, and J. P. Bolam (London: Elsevier), 59-87.

Farwell, J. R., Lee, Y. J., Hirtz, D. G., Sulzbacher, S. I., Ellenberg, J. H., and Nelson, K. B. (1990). Phenobarbital for febrile seizures - effects on intelligence and on seizure recurrence. N. Engl. J. Med. 322, 364-369. doi:10.1056/ NEJM199002083220604

Fishman, R. H. B., and Yanai, J. (1983). Long-lasting effects of early barbiturates on central nervous system and behavior. Neurosci. Biobehav. Rev. 7, 19-28.

Forcelli, P. A., Kozlowski, R., Snyder, C. Kondratyev, A., and Gale, K. (2012). Effects of neonatal antiepileptic drug exposure on cognitive, emotional, and motor function in adult rats. J. Pharmacol. Exp. Ther. 340, 558-566. doi:10.1124/ jpet.111.188862

Haberny, K. A., Paule, M. G., Scallet, A. C., Sistare, F. D., Lester, D. S., Hanig, J. P., et al. (2002). Ontogeny of the N-methyl-D-aspartate (NMDA) receptor system and susceptibility to neurotoxicity. Toxicol. Sci. 68, 9-17. doi:10.1093/toxsci/ 68.1 .9

Hannaert, P. H., Alvarez-Guerra, M.-G., Pirot, D. P., Nazaret, C. N., and Garay, R. G. (2002). Rat NKCC2/NKCC1 cotransporter selectivity for loop diuretic drugs. Naunyn Schmiedebergs Arch. Pharmacol. 365, 193-199. doi:10.1007/s00210-001-0521-y

Hansen, H. H., Briem, T., Dzietko, M., Sifringer, M., Voss, A., Rzeski, W., et al. (2004). Mechanisms leading to disseminated apoptosis following NMDA receptor blockade in the developing rat brain. Neurobiol. Dis. 16, 440-453. doi:10.1016/ j.nbd.2004.03.013

Herschkowitz, N. (1988). Brain development in the fetus, neonate and infant. Neonatology 54, 1-19. doi:10.1159/000242818

Holley, L., Turchi, J., Apple, C., and Sarter, M. (1995). Dissociation between the attentional effects of infusions of a benzodiazepine receptor agonist and an inverse agonist into the basal forebrain. Psychopharmacology (Berl.) 120, 99-108. doi:10.1007/ BF02246150

Holmes, G. L. (2004). Effects of early seizures on later behavior and epileptogenicity. Ment. Retard. Dev. Disabil. Res. Rev. 10, 101-105. doi:10.1002/ mrdd.20019

Huberfeld, G., Wittner, L., Clemenceau, S., Baulac, M., Kaila, K., Miles, R., et al. (2007). Perturbed chloride homeostasis and GABAergic signaling in human temporal lobe epilepsy. J. Neurosci. 27, 9866-9873. doi:10. 1523/JNEUROSCI.2761-07.2007

Ikonomidou, C., Scheer, I., Wilhelm, T., Juengling, F. D., Titze, K., Stöver, B., et al. (2007) Brain morphology alterations in the basal ganglia and the hypothalamus following prenatal exposure to antiepileptic drugs. Eur. J. Paediatr. Neurol. 11, 297-301. doi:10.1016/ j.ejpn.2007.02.006

Isenring, P., Jacoby, S. C., Chang, J., and Forbush, B. (1998). Mutagenic mapping of the Na-K-Cl cotransporter for domains involved in ion transport and bumetanide binding. 
J. Gen. Physiol. 112, 549-558. doi:10.1085/jgp.112.5.549

Jensen, F. E. (2009). Neonatal seizures: an update on mechanisms and management. Clin. Perinatol. 36, 881-900. doi:10.1016/j.clp.2009.08.001

Jevtovic-Todorovic, V., Hartman, R. E., Izumi, Y., Benshoff, N. D., Dikranian, K., Zorumski, C. F., et al. (2003). Early exposure to common anesthetic agents causes widespread neurodegeneration in the developing rat brain and persistent learning deficits. J. Neurosci. 23, 876-882.

Kahle, K. T., Barnett, S. M., Sassower, K. C., and Staley, K. J. (2009). Decreased seizure activity in a human neonate treated with bumetanide, an inhibitor of the $\mathrm{Na}^{+}-\mathrm{K}^{+}$$2 \mathrm{Cl}^{-}$cotransporter NKCC1. J. Child Neurol. 24, 572-576. doi:10.1177/0883073809333526

Kahle, K. T., Rinehart, J., De Los Heros, P., Louvi, A., Meade, P., Vazquez, N., et al. (2005). WNK3 modulates transport of $\mathrm{Cl}^{-}$in and out of cells: implications for control of cell volume and neuronal excitability. Proc. Natl. Acad. Sci. U.S.A. 102, 16783-16788. doi:10.1073/pnas.0508307102

Kahle, K. T., Rinehart, J., and Lifton, R. P. (2010). Phosphoregulation of the $\mathrm{Na}-\mathrm{K}-2 \mathrm{Cl}$ and $\mathrm{K}-\mathrm{Cl}$ cotransporters by the WNK kinases. Biochim. Biophys. Acta 1802, 1150-1158. doi:10.1016/j.bbadis.2010.07.009

Kahle, K. T., Ring, A. M., and Lifton, R. P. (2008a). Molecular physiology of the WNK kinases. Annu. Rev. Physiol. 70, 329-355. doi:10.1146/ annurev.physiol.70.113006.100651

Kahle, K. T., Staley, K. J., Nahed, B. V., Gamba, G., Hebert, S. C., Lifton, R. P., et al. (2008b). Roles of the cation-chloride cotransporters in neurological disease. Nat. Clin. Pract. Neurol. 4, 490-503. doi:10.1038/ncpneuro0883

Kaindl, A. M., Koppelstaetter, A., Nebrich, G., Stuwe, J., Sifringer, M., Zabel, C., et al. (2008). Brief alteration of NMDA or GABAA receptor-mediated neurotransmission has long term effects on the developing cerebral cortex. Mol. Cell. Proteomics 7, 2293-2310.

Khalilov, I., Holmes, G. L., and BenAri, Y. (2003). In vitro formation of a secondary epileptogenic mirror focus by interhippocampal propagation of seizures. Nat. Neurosci. 6, 1079-1085. doi:10.1038/ nn1125

Krafft, K., Lyon, D. O., and Poling, A. (1982). Effects of phenytoin on schedule-controlled performance of rats. Psychopharmacology (Berl.) 78, 93-95. doi:10.1007/ BF00470597

Loscher, W., Puskarjov, M., and Kaila, K. (2013). Cation-chloride cotransporters NKCC1 and KCC2 as potential targets for novel antiepileptic and antiepileptogenic treatments. Neuropharmacology 69, 62-74. doi:10.1016/ j.neuropharm.2012.05.045

Loturco, J. J., Owens, D. F., Heath, M. J. S., Davis, M. B. E., and Kriegstein, A. R. (1995). GABA and glutamate depolarize cortical progenitor cells and inhibit DNA synthesis. Neuron 15, 1287-1298. doi:10.1016/08966273(95)90008-X

Maa, E. H., Kahle, K. T., Walcott, B. P., Spitz, M. C., and Staley, K. J. (2011). Diuretics and epilepsy: will the past and present meet? Epilepsia 52, 1559-1569. doi:10.1111/j.15281167.2011.03203.x

Mares, P. (2009). Age- and dosespecific anticonvulsant action of bumetanide in immature rats. Physiol. Res. 58, 927-930.

Marty, A., and Llano, I. (2005). Excitatory effects of GABA in established brain networks. Trends Neurosci. 28, 284-289. doi:10.1016/j.tins.2005.04.003

Mazarati, A., Shin, D., and Sankar, R. (2009). Bumetanide inhibits rapid kindling in neonatal rats. Epilepsia 50, 2117-2122. doi:10.1111/j.15281167.2009.02048.x

Mikati, M. A., Holmes, G. L., Chronopoulos, A., Hyde, P., Thurber, S., Gatt, A., et al. (1994). Phenobarbital modifies seizure-related brain injury in the developing brain. Ann. Neurol. 36, 425-433. doi:10.1002/ana.410360314

Miles, R., Blaesse, P., Huberfeld, G. Wittner, L., and Kaila, K. (2012). "Chloride homeostasis and GABA signaling in temporal lobe epilepsy," in Jasper's Basic Mechanisms of the Epilepsies, 4th Edn, eds J. L. Noebels, M. Avoli, M. A. Rogawski, R. W. Olsen, and A. V. DelgadoEscueta (Bethesda: National Center for Biotechnology Information), 581-591.

Minlebaev, M., and Khazipov, R. (2011). Antiepileptic effects of endogenous beta-hydroxybutyrate in suckling infant rats. Epilepsy Res. 95, 100-109. doi:10.1016/ j.eplepsyres.2011.03.003

Munoz, A., Mendez, P., Defelipe, J., and Alvarez-Leefmans, F. J. (2007). Cation-chloride cotransporters and GABA-ergic innervation in the human epileptic hippocampus. Epilepsia 48 663-673. doi:10.1111/j.15281167.2007.00986.x

Nunez, J. L., Alt, J. J., and McCarthy, M. M. (2003). A novel model for prenatal brain damage. II. Long-term deficits in hippocampal cell number and hippocampaldependent behavior following neonatal $\mathrm{GABA}_{\mathrm{A}}$ receptor activation. Exp. Neurol. 181, 270-280.

Ostergaard, E. H., Magnussen, M. P., Nielsen, C. K., Eilertsen, E., and Frey, H. H. (1972). Pharmacological properties of 3-n-butylamino4-phenoxy-5-sulfamylbenzoic acid (Bumetanide), a new potent diuretic. Arzneimittel-Forschung 22, 66-72.

Painter, M. J., Scher, M. S., Stein, A. D., Armatti, S., Wang, Z., Gardiner, J. C., et al. (1999). Phenobarbital compared with phenytoin for the treatment of neonatal seizures. N. Engl. J. Med. 341, 485-489. doi:10.1056/ NEJM199908123410704

Palma, E., Amici, M., Sobrero, F., Spinelli, G., Di Angelantonio, S., Ragozzino, D., et al. (2006). Anomalous levels of $\mathrm{Cl}^{-}$transporters in the hippocampal subiculum from temporal lobe epilepsy patients make GABA excitatory. Proc. Natl. Acad. Sci. U.S.A. 103, 8465-8468. doi:10.1073/ pnas.0602979103

Pereira, M. E., Rosat, R., Huang, C. H., Godoy, M. G. C., and Izquierdo, I. (1989). Inhibition by diazepam of the effect of additional training and of extinction on the retention of shuttle avoidance behavior in rats. Behav. Neurosci. 103, 202-205. doi:10.1037/ 0735-7044.103.1.202

Rakhade, S. N., and Jensen, F. E. (2009). Epileptogenesis in the immature brain: emerging mechanisms. Nat. Rev. Neurol. 5, 380-391. doi:10.1038/nrneurol

Reid, K. H., Guo, S. Z., and Iyer, V. G. (2000). Agents which block potassium-chloride cotransport prevent sound-triggered seizures in post-ischemic audiogenic seizure-prone rats. Brain Res. 864, 134-137. doi:10.1016/ S0006-8993(00)02121-1

Rivera, C., Voipio, J., Payne, J. A., Ruusuvuori, E., Lahtinen, H., Lamsa, K., et al. (1999). The $\mathrm{K}^{+} / \mathrm{Cl}^{-}$cotransporter KCC2 renders GABA hyperpolarizing during neuronal maturation. Nature 397, 251-255. doi:10.1038/16697
Ronen, G. M., Penney, S., and Andrews, W. (1999). The epidemiology of clinical neonatal seizures in Newfoundland: a population-based study. J. Pediatr. 134, 71-75. doi:10. 1016/S0022-3476(99)70374-4

Schain, R. J., and Watanabe, K. (1975). Effect of chronic phenobarbital administration upon brain growth of the infant rat. Exp. Neurol. 47, 509-515. doi:10.1016/00144886(75)90083-7

Schwartzkroin, P. A., Baraban, S. C., and Hochman, D. W. (1998). Osmolarity, ionic flux, and changes in brain excitability. Epilepsy Res. 32, 275-285. doi:10.1016/S09201211(98)00058-8

Sulzbacher, S., Farwell, J. R., Temkin, N., Lu, A. S., and Hirtz, D. G. (1999). Late cognitive effects of early treatment with phenobarbital. Clin. Pediatr. (Phila.) 38, 387-394. doi:10.1177/000992289903800702

Swann, J. W. (2005). The impact of seizures on developing hippocampal networks. Prog. Brain Res. 147, 347-354. doi:10.1016/S00796123(04)47024-1

Swann, J. W., Brady, R. J., and Martin, D. L. (1989). Postnatal development of GABA-mediated synaptic inhibition in rat hippocampus. Neuroscience 28, 551-561. doi:10.1016/0306-4522(89)90004-3

Tekgul, H., Gauvreau, K., Soul, J., Murphy, L., Robertson, R., Stewart, J., et al. (2006). The current etiologic profile and neurodevelopmental outcome of seizures in term newborn infants. Pediatrics 117, 1270-1280. doi:10.1542/ peds.2005-1178

Wang, D. D., and Kriegstein, A. R. (2008). GABA regulates excitatory synapse formation in the neocortex via NMDA receptor activation. J. Neurosci. 28, 5547-5558. doi:10. 1523/JNEUROSCI.5599-07.2008

Wang, D. D., and Kriegstein, A. R. (2011). Blocking early GABA depolarization with bumetanide results in permanent alterations in cortical circuits and sensorimotor gating deficits. Cereb. Cortex 21, 574-587. doi:10.1093/cercor/ bhq124

Wisnowski, J. L., Blüml, S., Paquette, L., Zelinski, E., Nelson, M. D Jr., Painter, M. J., et al. (2013). Altered glutamatergic metabolism associated with punctate white matter lesions in preterm infants. PLoS ONE 8:e56880. doi:10.1371/journal.pone.0056880

Woodin, M. A., Ganguly, K., and Poo, M.-M. (2003). Coincident 
pre- and postsynaptic activity modifies GABAergic synapses by postsynaptic changes in $\mathrm{Cl}$ transporter activity. Neuron 39, 807-820. doi:10. 1016/S0896-6273(03)00507-5

Yanai, J., Bergman, A., Shafer, R., Yedwab, G., and Tabakoff, B. (1981). Audiogenic seizures and neuronal deficits following early exposure to barbiturate. Dev. Neurosci. 4, 345-350. doi:10.1159/ 000112774

Yanai, J., Fares, F., Gavish, M., Greenfeld, Z., Katz, Y., Marcovici, G., et al. (1989). Neural and behavioral alterations after early exposure to phenobarbital. Neurotoxicology 10, 543-554.

Yanai, J., Rosselli-Austin, L., and Tabakoff, B. (1979). Neuronal deficits in mice following prenatal exposure to phenobarbital. Exp. Neurol. 64, 237-244. doi:10.1016/0014-4886(79)90265-6

Conflict of Interest Statement: The authors declare that the research was conducted in the absence of any commercial or financial relationships that could be construed as a potential conflict of interest.

Received: 08 March 2013; accepted: 09 June 2013; published online: 25 June 2013.

Citation: Khanna A, Walcott BP and Kahle KT (2013) Limitations of current GABA agonists in neonatal seizures: toward GABA modulation via the targeting of neuronal $\mathrm{Cl}^{-}$ transport. Front. Neurol. 4:78. doi: 10.3389/fneur.2013.00078

This article was submitted to Frontiers in Epilepsy, a specialty of Frontiers in Neurology.

Copyright (C) 2013 Khanna, Walcott and Kahle. This is an open-access article distributed under the terms of the Creative Commons Attribution License, which permits use, distribution and reproduction in other forums, provided the original authors and source are credited and subject to any copyright notices concerning any third-party graphics etc. 